\title{
Waste Reduction and Improved Efficiency by Ion Chromatographic Method Modification (U)
}

by

A. A. Ekechukwu

Westinghouse Savannah River Company

Savannah River Site

Aiken, South Carolina 29808

\section{DISCLAIMER}

\begin{abstract}
This report was prepared as an account of work sponsored by an agency of the United States Government. Neither the United States Government nor any agency thereof, nor any of their employees, makes any warranty, express or implied, or assumes any legal liability or responsibility for the accuracy, completeness, or usefulness of any information, apparatus, product, or process disclosed, or represents that its use would not infringe privately owned rights. Reference herein to any specific commercial product, process, or service by trade name, trademark, manufacturer, or otherwise does not necessarily constitute or imply its endorsement, recommendation, or favoring by the United States Government or any agency thereof. The views and opinions of authors expressed herein do not necessarily state or reflect those of the United States Government or any agency thereof.
\end{abstract}

DOE Contract No. DE-AC09-89SR18035

This paper was prepared in connection with work done under the above contract number with the U.S. Department of Energy. By acceptance of this paper, the publisher and/or recipient acknowledges the U.S. Government's right to retain a nonexclusive, royalty-free license in and to any copyright covering this paper, along with the right to reproduce and to authorize others to reproduce all or part of the copyrighted paper.

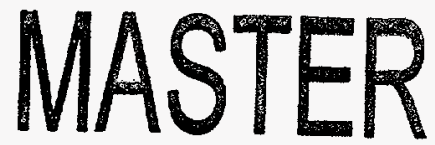




\section{DISCLAMMER}

Portions of this document may be illegible in electronic image products. Images are produced from the best available original document. 


\section{DISCLAIMER}

This report was prepared as an account of work sponsored by an agency of the United States Government. Neither the United States Government nor any agency thereof, nor any of their employees, makes any warranty, express or implied, or assumes any legal liability or responsibility for the accuracy, completeness, or usefulness of any information, apparatus, product, or process disclosed, or represents that its use would not infringe privately owned rights. Reference herein to any specific commercial product, process, or service by trade name, trademark, manufacturer, or otherwise does not necessarily constitute or imply its endorsement, recommendation, or favoring by the United States Government or any agency thereof. The views and opinions of authors expressed herein do not necessarily state or reflect those of the United States Government or any agency thereof.

This report has been reproduced directly from the best available copy.

Available to DOE and DOE contractors from the Office of Scientific and Technical Information, P.O. Box 62, Oak Ridge, TN 37831; prices available from (615) 576-8401.

Available to the public from the National Technical Information Service, U.S. Department of Commerce, 5285 Port Royal Road, Springfield, VA 22161. 


\title{
WASTE REDUCTION AND IMPROVED EFFICIENCY BY ION CHROMATOGRAPHIC METHOD MODIFICATION
}

\author{
Amy A. Ekechukwu \\ Savannah River Technology Center
}

\section{SUMMARY}

Our laboratory recently modified and upgraded our ion chromatography systems and methods to minimize waste generation and radiation exposure to employees. The following changes were made:

- Conversion to a 1-point linear calibration from a 4-point quadratic calibration;

- Replacement of chemical suppression system with an electrochemical suppression system;

- Adjustment of hydroxide-based gradient elution protocol to improve separation of fluoride and formate and shorten experimental run;

- Implementation of carbonate-based isocratic elution protocol

- Installation of lower capacity ion exchange columns which decrease analysis time by $50 \%$;

- Adjustment of detector output to achieve a ten-fold increase in sensitivity.

The combined changes decreased the analysis time by $90 \%$, decreased the liquid waste generated by the laboratory by $95 \%$, and lowered the detection limits by an order of magnitude.

\section{INTRODUCTION}

The Analytical Development group at the Savannah River Technology Center (SRTC) offers technical support to research programs in the laboratory as well as process control support for the rest of the Savannah River Site. A wide variety of sample types including groundwater, organics, laboratory waste, process control, sludge, and soils are received by the lab. Ion chromatography is one of the most commonly requested analyses in the laboratory, both for research and process control. The ion chromatography laboratory has nine complete systems in operation, including an automated dual-channel system for analyzing large batches of non-radioactive samples, two 
R\&D systems, and two units which are contained in a radiological hood for analysis of radioactive samples. In 1995, the ion chromatography lab processed approximately 8000 samples, most of which were submitted for anion analysis. The instrumentation in the IC laboratory ranges in age from three to ten years and there are several different models represented

Ion chromatography is used to determine common anions and cations in aqueous sample matrixes. In this analysis method, a sample is introduced into a flowing stream (mobile phase) which carries the sample through an ion exchange resin. Ions in the sample are separated by differential interaction with the resin and quantified through conductivity detection.

Originally, the analysis took approximately 30 minutes per sample run and generated approximately $200 \mathrm{~mL}$ of aqueous waste per run. On average, complete determination of the commonly requested anions (fluoride, formate, chloride, nitrite, nitrate, phosphate, sulfate, and oxalate) required three different dilutions (three runs) generating $600 \mathrm{~mL}$ of aqueous waste per sample. Cation analysis followed a similar pattern. Instrument calibration required eight 30minute runs (4 hours) to complete. Several method changes were tested and implemented; the combined effect of these changes was to decrease the liquid waste generated by $95 \%$, decrease the required sample volume by $90 \%$, lower the detection limits by an order of magnitude, and cut the analysis time by $90 \%$. The precision and accuracy were virtually unchanged.

\section{EXPERIMENTAL}

\section{Equipment Description}

The laboratory uses several different Dionex ion chromatographic (IC) systems. A Series 2000 basic IC is used for routine cation analysis (predominantly ammonium). A Series 4000 dual-channel advanced IC system is used for anion analysis, and a DX300 IC system is configured to run anions and cations. Some of the units are interfaced with computers which have been equipped with Dionex AI-450 software for data acquisition and instrument control while other systems are equipped with integrators. The laboratory contains both autosampler units and manual injection systems. The separated ions are detected and quantified using conductivity detection. The basic instrument diagram is shown in Figure 1. 
The anion columns used are low-capacity ion exchange guard and separator column sets available from Dionex. The most frequently used column set is the AG5A/AS5A column pair. An organic trap column (NG1, Dionex) is positioned just upstream from the guard column to remove organics which could damage the columns and suppressor membranes. The cation column used is a low capacity cation exchange column set (CG3/CS3) also available from Dionex. Suppression of background eluent conductivity is achieved using the Dionex Self Regenerating Suppressor (SRS) system.

\section{Standards Preparation}

Custom prepared standards are procured from Dionex. The anion standards contain $1000 \mathrm{ppm}(\mathrm{ug} / \mathrm{mL}$ ) of the eight anions routinely analyzed (fluoride, formate, chloride, nitrite, nitrate, sulfate, phosphate, and oxalate). A $1000 \mathrm{ppm}$ ammonium standard is also procured from Dionex. These standards are volumetrically diluted to different concentrations from 1 to $10 \mathrm{ppm}$ and used as calibration standards.

\section{DISCUSSION}

All method changes described below were tested on a DX300 system and run concurrently with the original protocols before changes were implemented.

\section{Calibration}

There are two types of instrument calibrations which can be performed: linear, which uses one standard concentration value, and quadratic, which uses multiple standard concentration values. A one-point linear calibration has the advantage of being fast but has a narrower concentration range over which the calibration is valid, generally $10 \%$ to $200 \%$ of the standard value. A quadratic calibration takes longer to perform, but the calibration is valid over a wider concentration range, generally from 0 to $500 \%$ of the highest standard value. Thus a quadratic calibration requires fewer dilutions of a sample to obtain accurate data.

The IC lab was using a four-point quadratic equation which calibrated the instrument using $1,2,10$, and $20 \mathrm{ppm}$ standards for each ion. Combined with the blanks and check standards, the calibration took a total of eight 30-minute runs. The calibration was changed to a one-point linear calibration which required three runs (calibration, blank, and check standard). Since many of the samples 
run by the lab are well characterized and the required dilution is known, the faster linear calibration offers a significant time savings.

\section{Accuracy and Precision of Measurements}

Using 1 and $10 \mathrm{ppm}$ standards, the precision of anion and cation analysis is between $+/-1$ and 3\% RSD. This is comparable to precision using the previous method. The data obtained for samples analyzed using the existing (hydroxide) method and the new (carbonate) method agree within 5\%. Table 1 shows the results for anion standards which were analyzed using both the original and revised methods.

\section{Electrochemical Suppression}

The ICs in our laboratory have a suppression system which is used to decrease or "suppress" the conductivity of the eluent mobile phase. The original suppression system on the ICs was a counter-current ion exchange system. Once the sample had passed through the anion exchange resin (for anion analysis) and the anions in solution $h$ ad been separated, the eluent stream was passed through a cation exchange resin. The separated anions passed through unaffected, but the cations in the eluent (predominantly sodium) were exchanged for hydrogen ions contained in a counter-current (regenerant) stream. This converted the eluent to a weak acid with very low conductivity. In comparison to the eluent stream which flowed at $1 \mathrm{~mL}$ per minute, the regenerant stream flowed at 4 to $5 \mathrm{~mL}$ per minute and so represented $80 \%$ of the liquid waste generated.

This suppression system was replaced with an electrochemical suppression system which produces a regenerant stream by electrochemical reduction of the waste from the eluent stream. The self regenerating suppressor (SRS) employs a self-contained electrochemical membrane and thus requires no preparation of reagents. It is therefore less time consuming and less costly that the previous system. The cost of the SRS membranes is the same as that of the counter-current suppressor membranes. Minimal instrument and procedural modifications were required. Because it cathodically generates hydrogen ions in proportion to the cation concentration in the eluent stream, the electrochemical suppressor is more effective than the chemical suppression system at decreasing the background conductivity. This lower background conductivity enabled modification of the detector to increase the sensitivity of the analysis by an order of magnitude. The lower detection limit decreased the required sample volume by $90 \%$. 
Adjustment of Hydroxide-Based Gradient Elution Protocol Using the original hydroxide-based gradient elution protocol, fluoride and formate eluted so closely together that it was extremely difficult to calibrate for both anions on the same system. One system was therefore dedicated to formate analysis alone and the other system was used for determination of the other seven anions including fluoride. The gradient elution program was adjusted to better separate fluoride and formate to enable calibration of the same system. These two anions could then be measured in one experimental run instead of two. The elution protocol was further adjusted to speed-up the elution of the larger ions and shorten the experimental run. The hydroxide protocol which originally took two 30 -minute runs on two separate systems can now be accomplished in one 12-minute run. The chromatogram for the anions standard using both the original and the revised gradient hydroxide elution protocol are shown in Figures 2 and 3.

\section{Carbonate Elution Protocol}

The lab was using a sodium hydroxide based eluent. Sodium hydroxide, which can have a lower baseline when running caustic samples, is difficult to work with because it absorbs carbon dioxide readily from the air. It must therefore be sparged and blanketed with helium while in use. Even in this inert atmosphere, it is stable for only 72 hours. The hydroxide method employed also used a gradient elution program, meaning the concentration of the hydroxide was varied during the experimental run. This lengthened the analysis and caused baseline drift which had a deleterious effect on the precision of the measurements. This method was originally set up to enable better separation of fluoride and formate in caustic samples.

Advances in detection and column design have decreased the interference of early eluting anions like fluoride and formate using carbonate eluent. Carbonate eluent is more stable than hydroxide and gives narrower, faster eluting peaks. The anions can all be eluted in 5 to 15 minutes, depending on column type, using an isocratic elution protocol. In isocratic elution, the concentration of the eluent remains constant during the experimental run so there is very little change in background conductivity (i.e.: there is a stable baseline). The chromatogram for anion analysis using isocratic carbonate elution is shown in Figure 4. One of the anion systems was converted to carbonate eluent with an isocratic separation protocol. 
The column was changed to a lower capacity column (described below) which elutes all anions in 7 minutes.

\section{Low Capacity Ion Exchange Columns}

The separation of ions is effected by passage through a low capacity ion exchange column. As stated previously, the original columns required 30 minutes for complete separation of anions and 15 minutes for complete separation of cations. These columns were replaced by lower capacity ion exchange columns (called "fast-sep" columns) which effect the same separation in 5 to 10 minutes. Since the amount of waste generated by the instrument is based on the length of an analysis run, this change decreased the waste generated per sample by $75 \%$. The precision of the data, $+/-3$ to $5 \%$ depending on the sample matrix, is equal to that of the original columns.

The fast-sep column is of lower capacity that the previous column so is more prone to irreversible loading damage (poisoning) when running concentrated samples. However, the column has proven to be fairly resilient and can be easily cleaned and regenerated after poisoning by concentrated samples. The column lifetime is comparable to the previous column (12 to 18 months on average).

\section{Detection Limits}

The detection limits for all ions measured was $1 \mathrm{ppm}$. As described in the preceding section, the electrochemical suppression system lowered the background conductivity and hence decreased the background noise of the conductivity detector. The detector was adjusted to improve the detection limits by an order of magnitude. These results agree within $5 \%$ in all cases. Standard values, allowing for dilution, agree within $3 \%$.

\section{CONCLUSION}

We implemented changes in our ion chromatography lab to which lowered detection limits, decreased analysis time, decreased waste generation and radiation exposure. The addition of the carbonatebased eluent method offered expanded technical support. The changes made in the laboratory were inexpensive and did not require purchase of capital equipment. This demonstrates that significant improvements can be made with simple modifications to existing methodologies. 
Table 1: Anion Standard Results for Old and New Methods (\%RSD)

$\begin{array}{llll}\text { Anion } & \text { Prepared Value } & \text { Old System } & \text { New System } \\ \text { Fluoride } & 2 \mathrm{ppm} & 2.02(1.7) & 2.02(1.4) \\ \text { Formate } & 10 \mathrm{ppm} & 10.03(2.6) & 10.04(1.9) \\ \text { Chloride } & 2 \mathrm{ppm} & 1.98(1.5) & 2.01(2.5) \\ \text { Nitrite } & 10 \mathrm{ppm} & 9.97(2.3) & 10.11(2.0) \\ \text { Nitrate } & 10 \mathrm{ppm} & 9.80(1.8) & 9.91(2.7) \\ \text { Phosphate } & 10 \mathrm{ppm} & 10.09(2.5) & 9.87(2.5) \\ \text { Sulfate } & 10 \mathrm{ppm} & 10.11(2.8) & 10.05(1.8) \\ \text { Oxalate } & 10 \mathrm{ppm} & 10.15(2.4) & 10.11(2.5)\end{array}$


Figure 1: Basic Ion Chromatography Instrument Diagram - Eluent is pumped through a separator column. The sample is injected into this stream and passes through the column which separates the anions in the sample. The separated anions pass through a conductivity cell, the conductivity is recorded and the chromatogram generated. The effluent from the cell is routed through a suppressor membrane which lowers the background conductivity of the eluent and enables detection of the separated anions. Effluent from the suppressor membrane goes to waste.

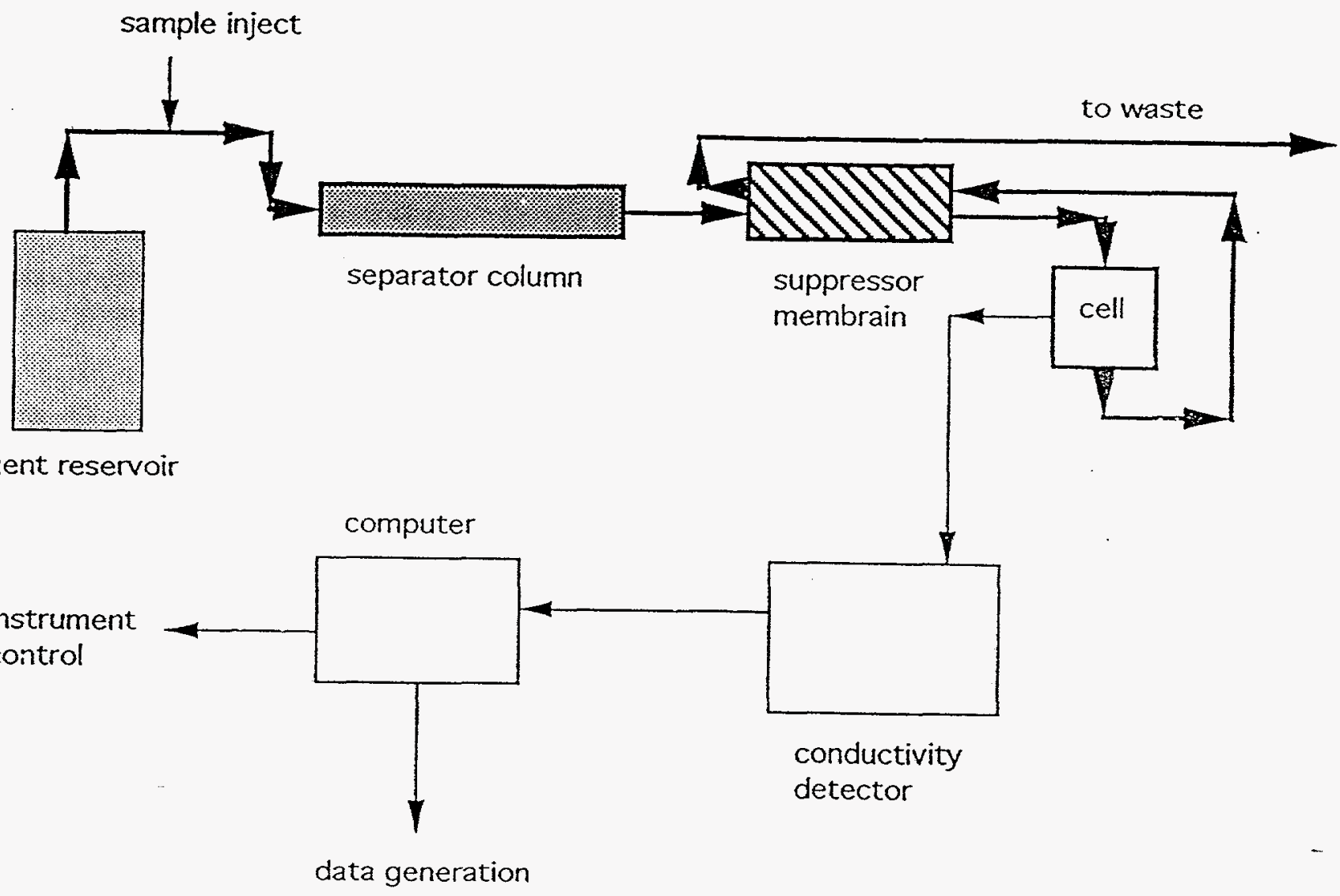


Figure 2: Anion Standard: Original method using hydroxide eluent. gradient elution, and chemical suppression

File: naoh6711.D08 Sample: STD

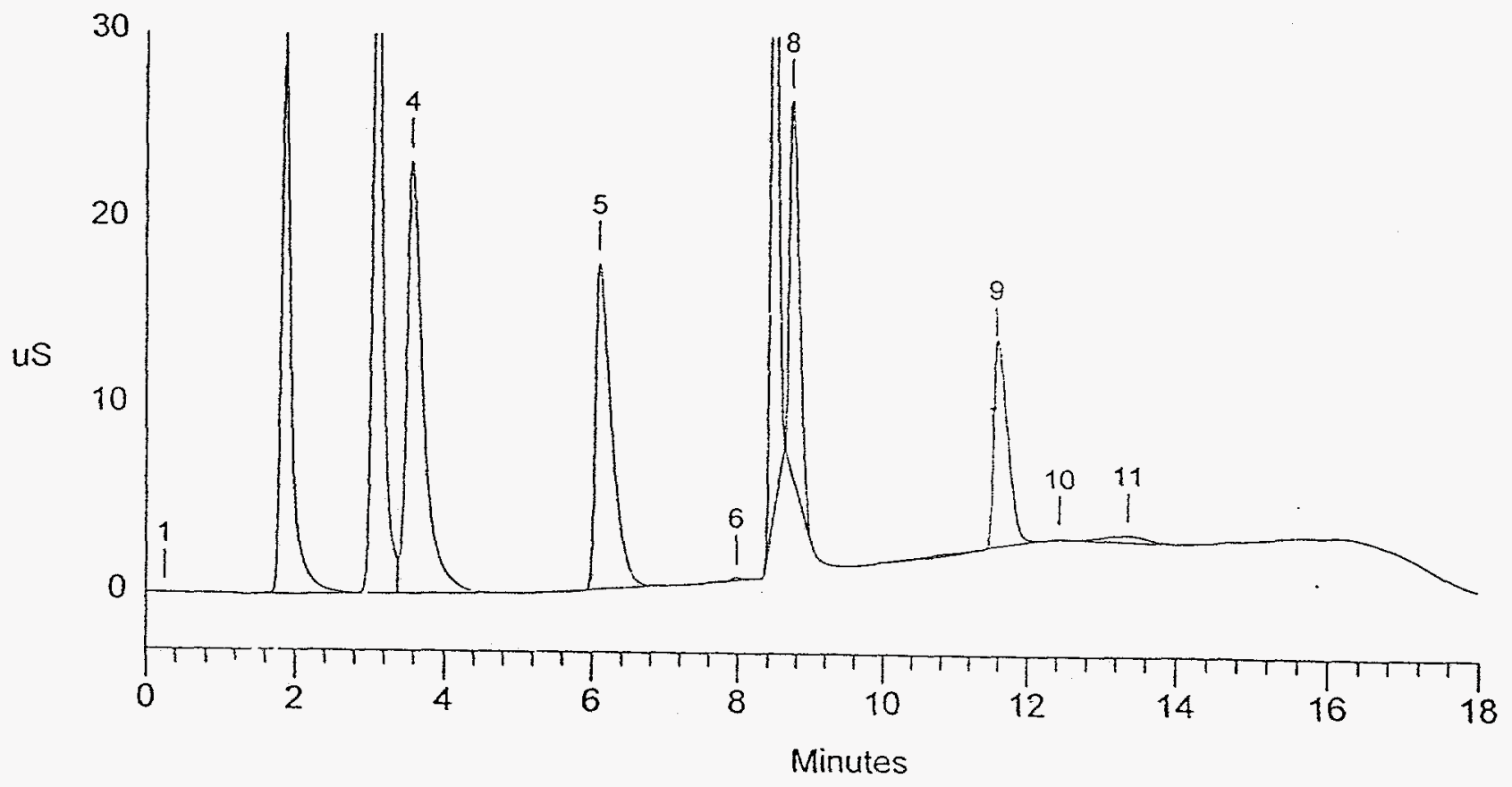


Figure 3: Anion Standard: Revision of method using hydroxide eluent, gradient elution, and electrochemical suppression

File: DATA0421.D06 Sample: STD

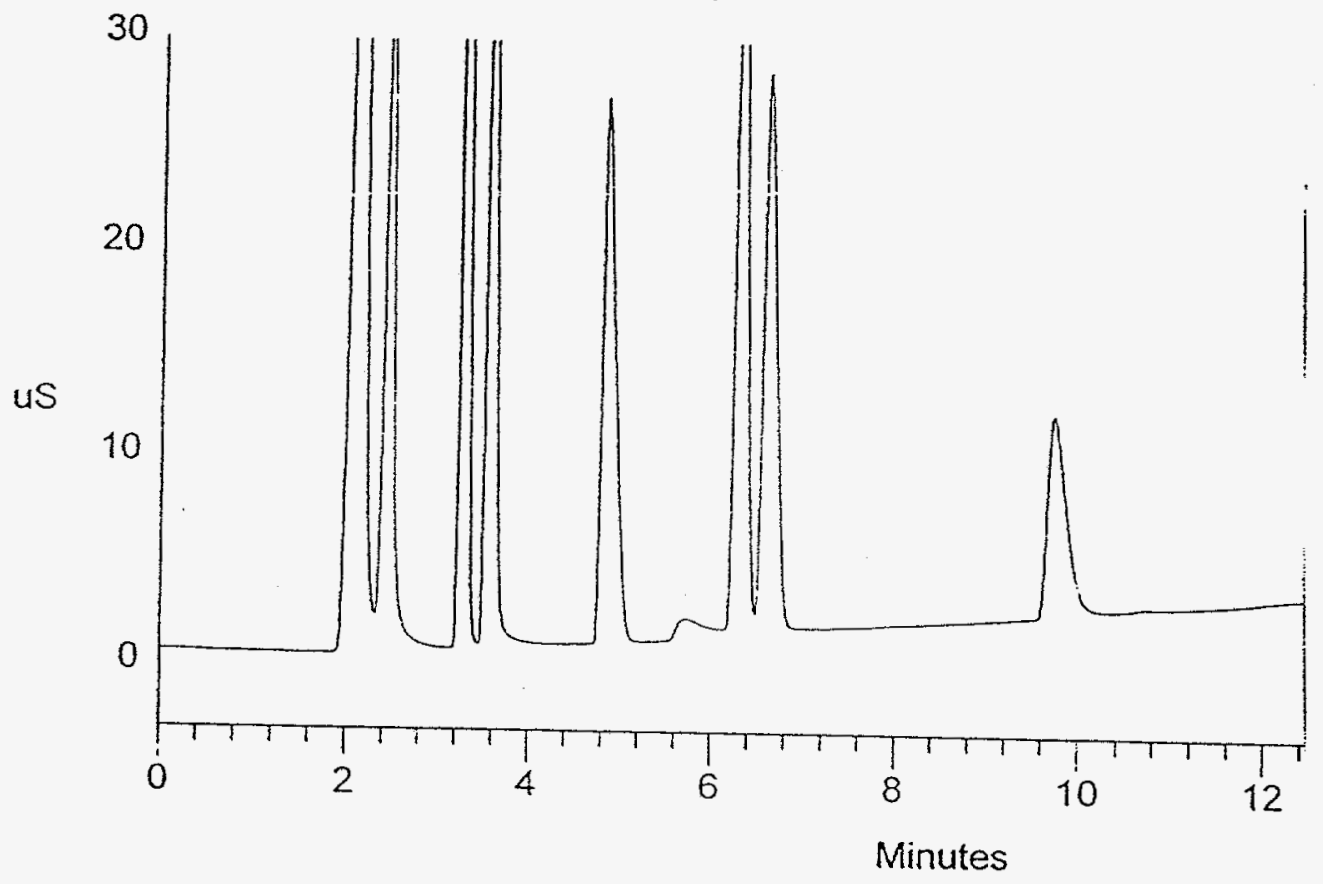




\section{WSRC-MS-96-0504}

Figure 4: Anion Standard: Carbonate eluent, isocratic elution, and electrochemical suppression

File: AMY00011.D01 Sample: AUTOCALR

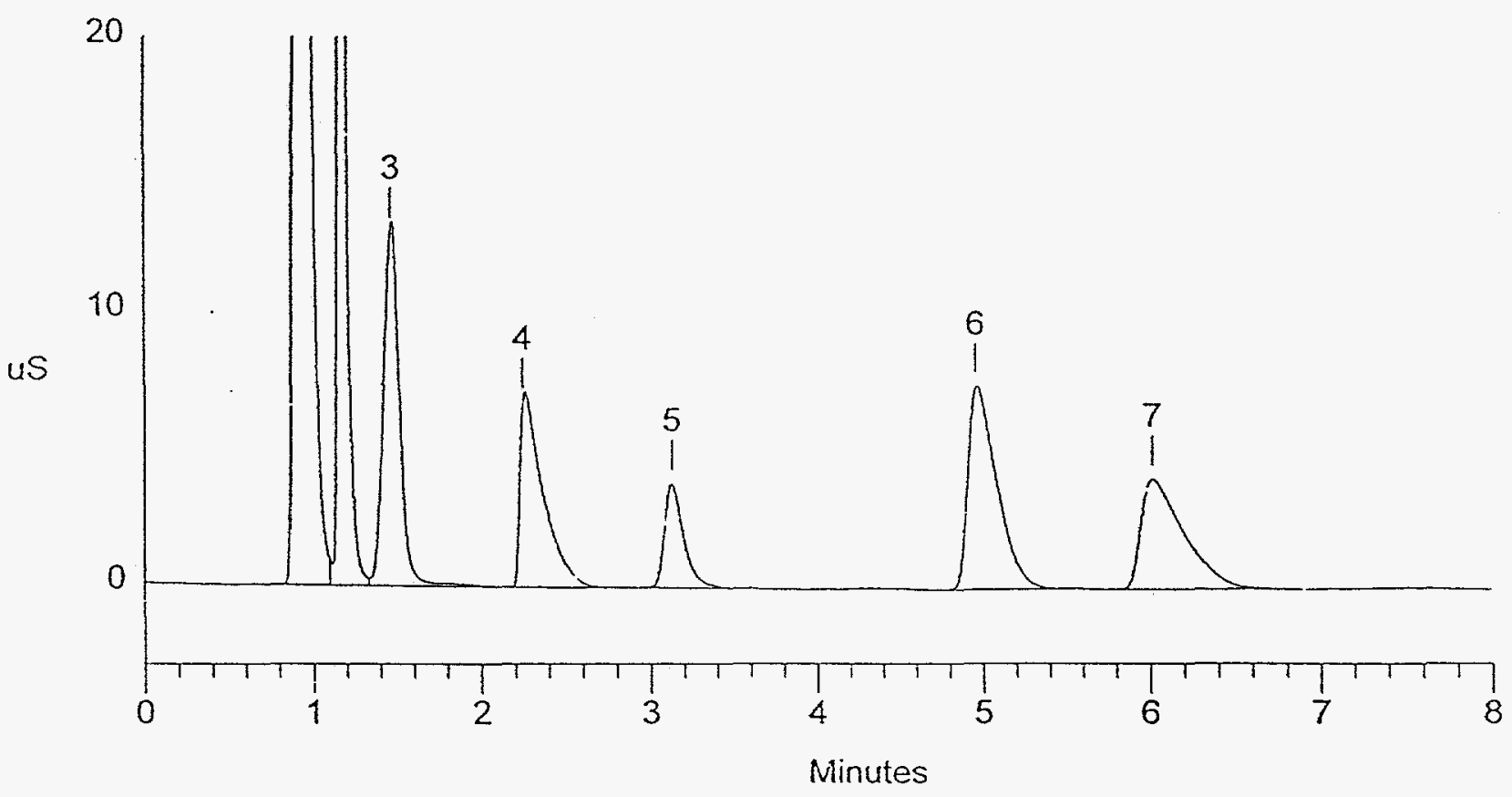

